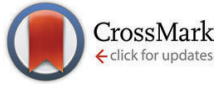

Cite this: Phys. Chem. Chem. Phys., 2015, 17, 22758

Received 26th May 2015, Accepted 21st July 2015 DOI: $10.1039 / c 5 c p 03013 g$

www.rsc.org/pccp

\title{
The optical properties and quantum chemical calculations of thienyl and furyl derivatives of pyrene
}

\author{
Krzysztof R. Idzik, ${ }^{\star a}$ Piotr J. Cywiński, ${ }^{\text {b }}$ Wojciech Kuznik, ${ }^{c}$ Jaroslaw Frydel, ${ }^{d}$ \\ Tobias Licha a and Tomasz Ratajczyk ${ }^{\mathrm{e}}$
}

\begin{abstract}
A detailed electrochemical, photophysical and theoretical study is presented for various new thienyl and furyl derivatives of pyrene. Their optical properties are described based on UV-VIS absorption and both steady-state and time-resolved fluorescence spectroscopy. DFT and TDDFT calculations are also presented to support experimental data. The calculations results show that HOMO-LUMO orbitals are delocalized uniformly between aromatic core and aryl substituents. Good electrochemical stability of thienyl and furyl hybrids of pyrene confirm their potential application for light emitting electrochemical cells or spintronics mainly due to their beneficial optical and charge transport properties in electrochromic devices. In order to demonstrate this potential, an OLED device is presented. Synthesized compounds included in this OLED device both facilitate electron transport and act as a light emitting layer.
\end{abstract}

\section{Introduction}

Organic materials possessing an extended $\pi$-conjugation have received immense attention in recent years. This is due to their unique photophysical and charge transport properties, which make them potential materials for applications in electronic devices such as organic light emitting diodes (OLEDs), ${ }^{1-8}$ organic photovoltaics (OPV), ${ }^{9-15}$ or organic thin film transistors (OTFT). ${ }^{16-20}$ Further, they are attractive due to their promising two photon absorption $^{21-24}$ and nonlinear optical ${ }^{21-24}$ characteristics.

Fluorescence probes based on pyrene moieties have attracted considerable attention over the past decades. ${ }^{25-32}$ The pyrene ring is of special interest because its hydrogen atoms can easily be substituted using a wide range of chemical groups, particularly aryl groups such as thiophene or furan. The pyrene structure is well studied and has been intensively examined in the fields of biology, chemistry and physics. Moreover, due to its electroconductive properties, pyrene and its derivatives have been successfully applied as micro-environmental sensors, ${ }^{33-36}$

\footnotetext{
${ }^{a}$ Geoscience Centre of the University of Göttingen, Dept. Applied Geology, Goldschmidtstr. 3, 37077 Göttingen, Germany. E-mail: krzysztof.idzik@pwr.wroc.pl

${ }^{b}$ Functional Materials and Devices, Fraunhofer Institute for Applied Polymer Research, Geiselbergstr. 69, 14476 Potsdam-Golm, Germany

${ }^{c}$ Czestochowa University of Technology, Faculty of Electrical Engineering, Armii Krajowej 17, 42-201 Czestochowa, Poland

${ }^{d}$ VENITUR Sp. z o.o., Wawozowa 34 B, 31-752 Krakow, Poland

${ }^{e}$ Polish Academy of Sciences, Institute of Physical Chemistry, Kasprzaka 44/52, 01-224 Warsaw, Poland
}

liquid crystals, ${ }^{37,38}$ and photoactive polypeptides. ${ }^{39}$ Pyrene is a flat aromatic molecule and exhibits excellent fluorescence properties. Its pure blue emission already permits its exploitation for its use in OLEDs. ${ }^{40}$ The pyrene core is particularly interesting in this context, since it offers numerous possibilities for peripheral group modifications with profound consequences on the condensed-matter structure. For example, unsubstituted pyrene forms monoclinic crystals, while tetraethynylpyrene derivatives of phenylethynyl form liquid crystalline columnar phases, ${ }^{41}$ and pyrenes similarly substituted with diethyleneglycolether derivatives display a liquid phase at room temperature. ${ }^{42}$ Pyrene is an efficient luminescent material, which has been investigated for several decades. However, self-quenching can be observed at high concentrations or pure crystals due to a molecular aggregation via $\pi$-stacking. ${ }^{43-45}$ However, the luminescence properties of the pyrene core might be modulated using the proper molecular substitution, e.g., with heterocyclic units.

Organic $\pi$-conjugated structures containing thiophene units play an important role in the search for new materials and their novel applications ${ }^{46}$ such as organic solar cells ${ }^{47,48}$ or organic field effect transistors. ${ }^{49}$ Thiophenes with well-defined chemical structures have recently attracted great attention not only as an example of model compounds for conducting materials, but also as a new class of functional $\pi$-electron systems. ${ }^{50-56}$

Furan-based polymers are among the most widely used $\pi$-conjugated systems in organic electronic devices. For example, polymers containing furyl groups show an excellent performance when acting as building materials for a highly efficient OLEDs. ${ }^{57}$ Another reason for using furan is its lower resonance stabilization 


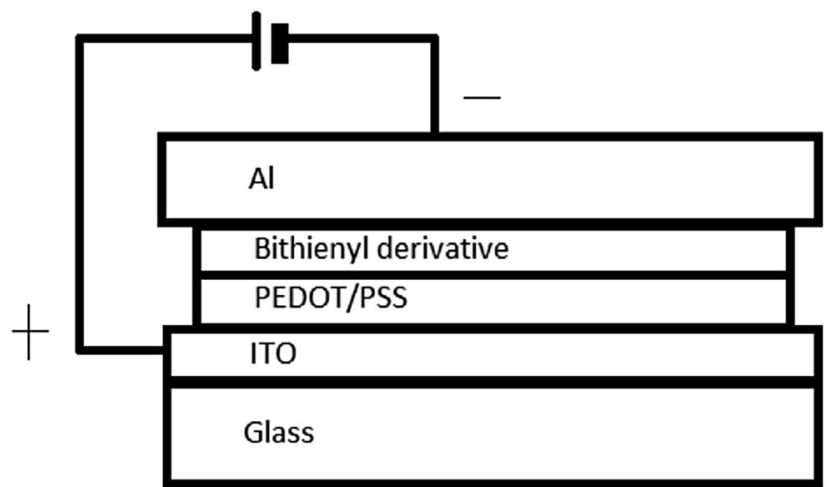

Fig. 1 OLED structure with the details of the organic materials and their functions used in each layer.

energy compared to benzene. Thus, chromophores with furan moieties display a molecular hyperpolarizability, which is higher than those of their their benzene analogues. ${ }^{58}$ Oligofurans with well-defined structures have also received great attention, not only exemplarily as model compounds for conducting polyfurans, but also as a new class of functional $\pi$-electron systems.

Considering the current literature, one can conclude that, when compared to other heteroaromatics such as thiophene or pyrrole, furan has great potential for further studies. ${ }^{59-66}$ This may partially be attributed to the chemical lability of furan and its derivatives. For example, furan serves as a diene in the [4+2] Diels-Alder reactions under milder conditions than those for thiophene and pyrrole. ${ }^{67}$ On the other hand, the relatively low aromaticity of furan compared to those of thiophene and pyrrole may give rise to different electronic properties in the resulting furan-based materials. ${ }^{68}$

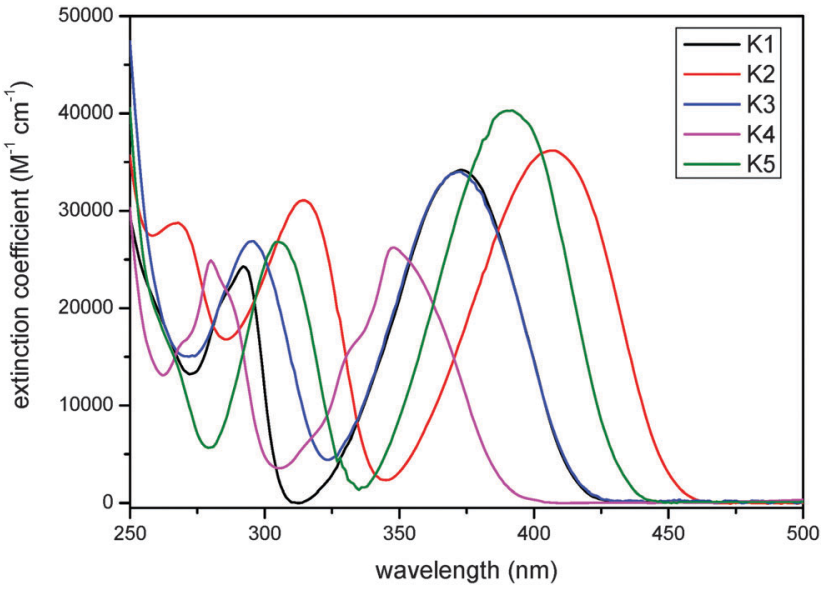

Fig. 2 Electronic absorption spectra for all pyrene thiophene derivatives in chloroform (in ex. coefficient units).

Over the last decade, highly efficient blue OLEDs have attracted considerable attention due to their potential applications in full color ultra-thin flat panel displays. ${ }^{69-75}$ Organic light sources are currently made from either low molecular weight organic materials or polymers. For the former, the layer structure of the OLED is usually deposited on a rigid base made from glass or metal. ${ }^{76-79}$

Suzuki, Stille, Kumada, and Negishi coupling reactions are well-described synthetic methods that are often used to prepare electroactive compounds. In this paper, we also present a series of symmetric molecules in which a pyrene core is connected to thiophene and furan units. All compounds were obtained using the Stille cross-coupling reaction. Furthermore, we describe DFT

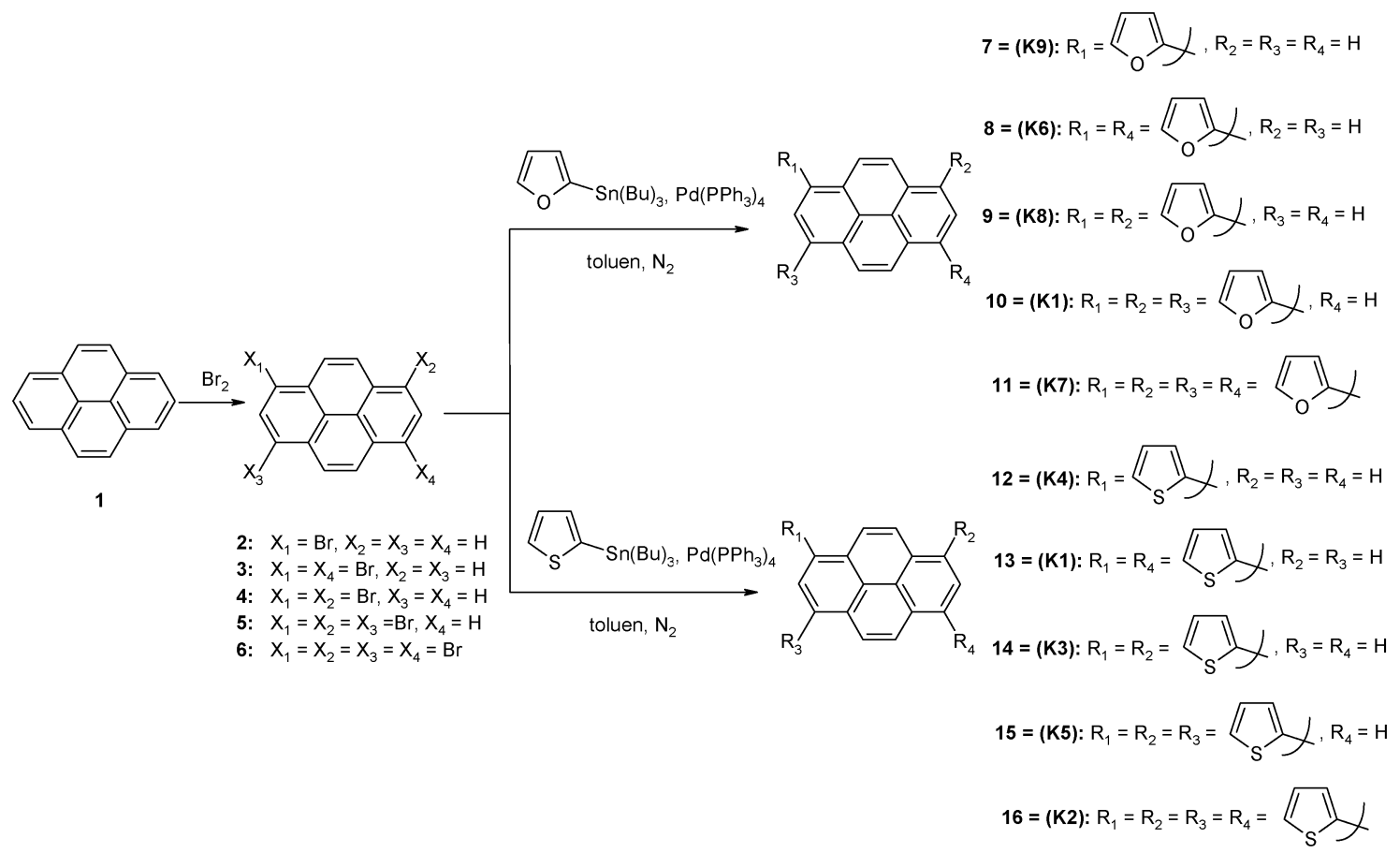

Scheme 1 Synthesis of thienyl and furyl derivatives of pyrene. 
calculations and TDDFT simulations of molecular materials based on a pyrene core which is connected to thiophene and furan units. We also report the results of UV-VIS and fluorescence spectroscopy measurements for the obtained compounds. Additionally, we present a fully functioning OLED device using a synthesized low molecular weight material to act as an electron transporting and light emitting layer (Fig. 1).

\section{Methods and materials}

\subsection{Synthesis}

All chemicals, reagents, and solvents were used as received from commercial sources without further purification. Melting points of the synthesized dyes were determined using a Stuart smp 20 melting point apparatus.

\subsection{Optical measurements}

Electronic absorption spectra were collected on a UV-VIS absorption spectrometer Lambda 35 (Perkin Elmer, Rodgau, Germany). The spectra were corrected with solvent absorption spectra to obtain final absorption spectra for the studied compounds. Steady-state fluorescence emission spectra were collected on an FLS920-stm spectrometer (Edinburgh Instruments, Livingstone, United Kingdom). The spectra were detector response corrected. Fluorescence decays were also acquired on the FLS920-stm spectrometer using the Time Correlated Single Photon Counting (TCSPC) technique with a sub-nanosecond pulsed LED (EPLED 320) as an excitation source. Fluorescence decay times were determined from the decays using the least squares fit method. The fitting was assumed to be correct when the goodness-of-fit value $\chi^{2}$ was lower than 1.2. Fluorescence quantum yields were measured on a C9920-02G absolute quantum yield $(\Phi)$ measurement system from Hamamatsu (Hamamatsu Photonics Deutschland GmbH, Herrsching am Ammersee, Germany). All measurements were performed using a $3 \mathrm{ml}$ quartz cuvette (Hellma $\mathrm{GmbH}$, Germany) with $1 \mathrm{~cm}$ light path. All measurements were obtained for samples with optical densities below 0.15 .

\subsection{Quantum-chemical calculations}

All quantum mechanical calculations were made at the DFT level using the GAUSSIAN09 package ${ }^{80}$ and GABEDIT 2.4.6 Graphical User Interface. ${ }^{81}$ The $6-31 G^{*}$ basis set and the B3LYP functional were used. The polarizable continuum model (PCM) was used in all calculations to account for the solvent influence (chloroform). ${ }^{82}$ The absorption and emission spectra and excited state geometries were obtained from time dependent DFT (TDDFT) singlet calculations. The reported lowest unoccupied molecular orbitals (LUMO) energy values are read as DFT highest occupied molecular orbital (HOMO) level reduced by the TDDFT energy gap.

\subsection{OLED preparation}

Indium tin oxide (ITO)-coated glass with a sheet resistance of about 8-12 $\Omega \mathrm{sq}^{-1}$ (Sigma-Aldrich) was used for preparing the OLED, while the cathode was made from Al. The hole-conductive layer (HTL) was PEDOT: PSS poly(3,4-ethylenedioxythiophene):

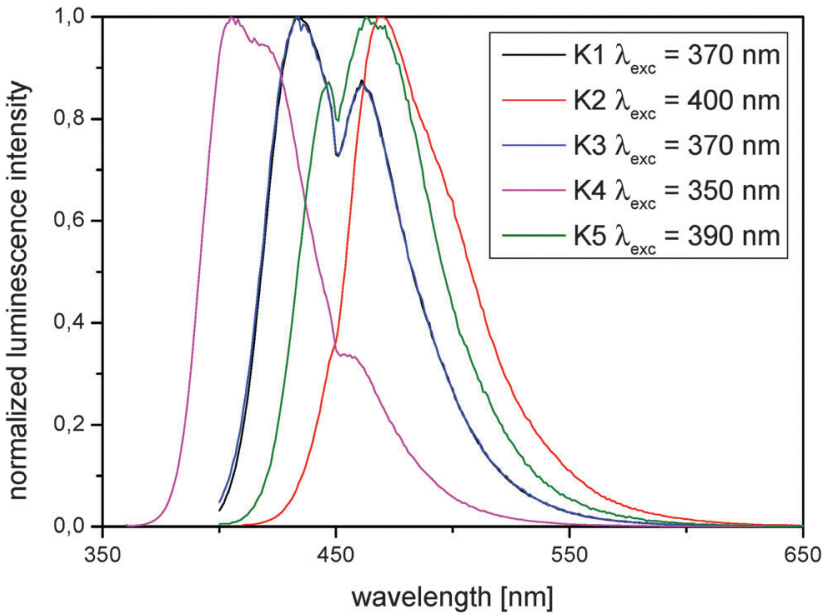

Fig. 3 Normalized fluorescence emission spectra for all dyes in chloroform.

poly(styrenesulfonate) (Sigma-Aldrich). Synthesized low molecular materials were used for the preparation of the light-emitting layer (EML). All measurements were performed using laboratory power supply EA-PS 2032-025 (Fig. 1).

\section{Results and discussion}

\subsection{Synthesis}

The chemical structure and synthetic route to the pyrene derivatives are illustrated in Scheme 1. Bromination of pyrene (1) with one to four equivalents of bromine gave the mono-, di-, tri-, and tetrabromopyrenes, respectively. The bromination resulted in 1-bromopyrene (2), 1,6-dibromopyrene (3) or 1,4-dibromopyrene (4), 1,3,6-tribromopyrene (5), and 1,3,6,8-tetrabromopyrene (6), ${ }^{21}$ respectively. Mono- and dibromopyrene were prepared in DCM, while in the case of tri- and tetrabromopyrene we used nitrotoluene as a solvent. The cross-coupling reaction of these bromopyrenes with 2-(tributylstannyl)furan under the conditions of the Stille reaction gave mono-, bis-, tris-, and tetrakis(furyl) pyrenes 7-11, respectively. For the preparation of di(furyl)pyrenes we used

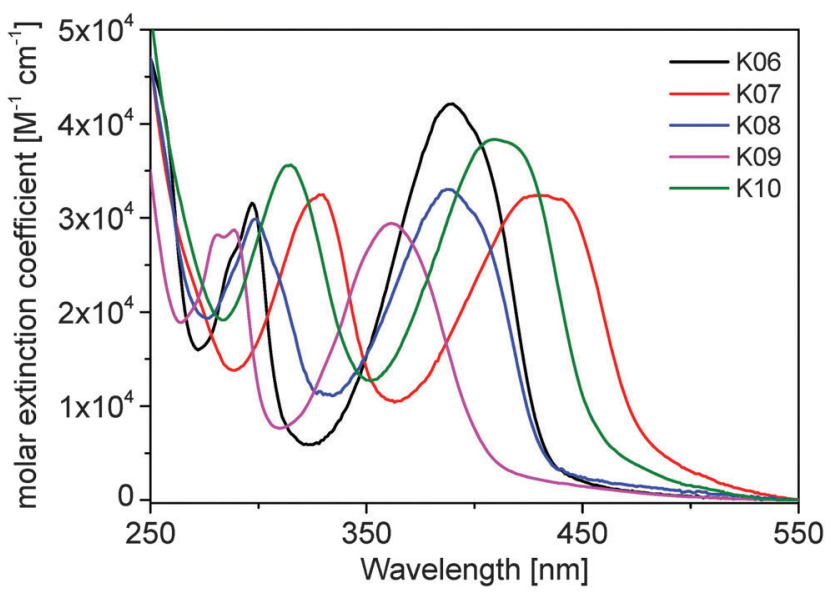

Fig. 4 Electronic absorption spectra for all dyes in chloroform (in ex. coefficient units) 
Table 1 Absorption and emission properties of the studied thienyl derivatives of pyrene

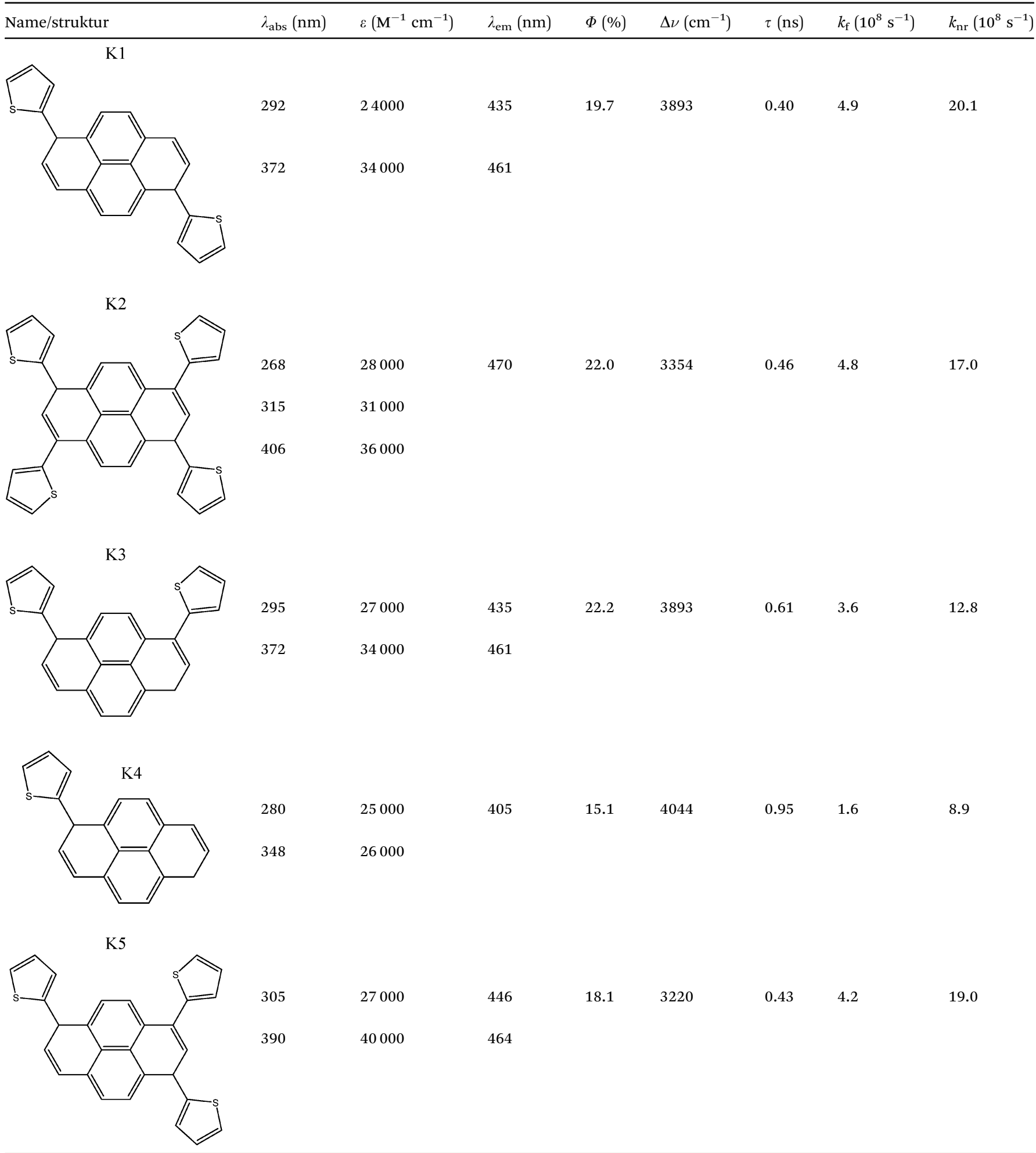

a mixture of 1,6-dibromopyrene (3) and 1,4-dibromopyrene (4). We successfully isolated 1,6-di(furyl)pyrene (8) from 1,4-di(furyl)pyrene (9). Instead of 2-(tributylstannyl)furan we used 2-(tributylstannyl)thiophene to prepare the thienyl derivative of pyrenes 12-15. The reactions were conducted under easy-to-perform, mild conditions with moderate to good yields. All compounds studied in this work were obtained by the Stille cross-coupling methodology according to the procedure reported in our previous work (Scheme 1). ${ }^{83-86}$ Table 7 presents the melting points of the synthesized dyes. 
Table 2 Absorption and emission properties of the studied furyl derivatives of pyrene

Name/structure $\quad \lambda_{\text {abs }}(\mathrm{nm}) \quad \varepsilon\left(\mathrm{M}^{-1} \mathrm{~cm}^{-1}\right) \quad \lambda_{\mathrm{em}}(\mathrm{nm}) \quad \Phi(\%) \quad \Delta \nu\left(\mathrm{cm}^{-1}\right) \quad \tau(\mathrm{ns}) \quad k_{\mathrm{f}}\left(10^{8} \mathrm{~s}^{-1}\right) \quad k_{\mathrm{nr}}\left(10^{8} \mathrm{~s}^{-1}\right) \quad$

K6<smiles>C1=CC(c2ccco2)c2ccc3c4c(ccc1c24)C=CC3c1ccco1</smiles>

297

390

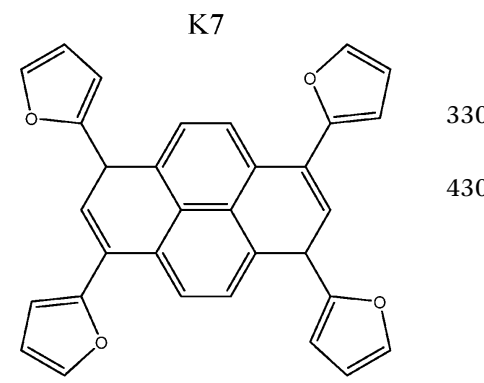

K8<smiles>C1=CC(c2ccco2)c2ccc3c4c(ccc1c24)CC=C3c1ccco1</smiles>

33000

433

68.7

2679

3.6

1.6
29000

403

29000

423

315

35000

460

$63.2 \quad 2651$

39000

480

$\begin{array}{llll}38.2 & 2810 & 3.3 & 1.2\end{array}$

1.9

410
63

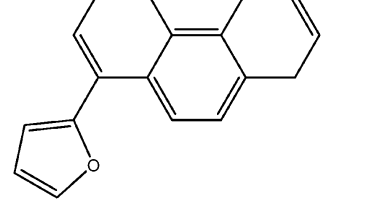

The derivative containing four thiophenes exhibits similar absorption features to pyrene; however, the spectrum displays a significant red shift. This feature can be associated with pyrene or furan electron transitions mixed with the transitions characteristic for thiophene. Depending on the derivative, the higher energy transitions (presumably $\pi \rightarrow \pi^{*}$ ) can be observed in the 


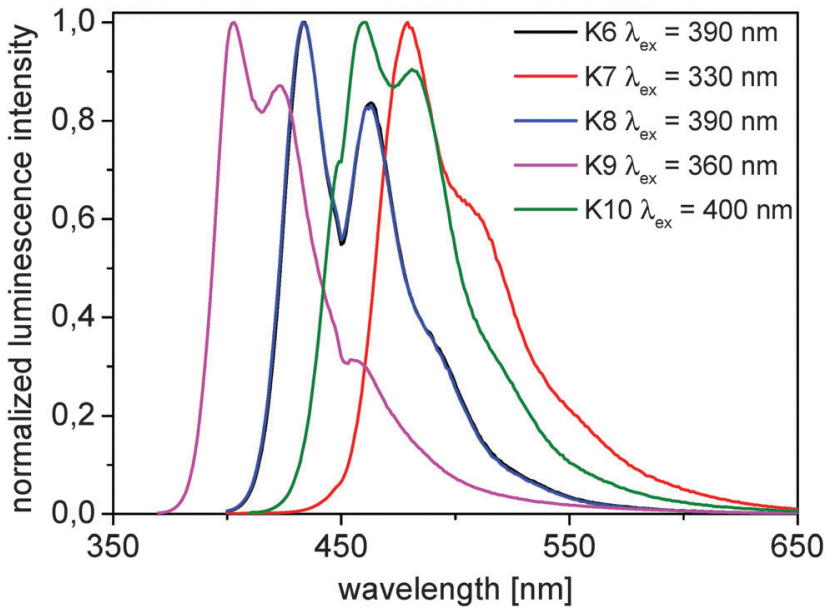

Fig. 5 Normalized fluorescence emission spectra for all dyes in chloroform.

range of 280-315 $\mathrm{nm}$, while the lower energy transitions (presumably $\mathrm{n} \rightarrow \pi^{*}$ ) can be found in the spectral range between $350 \mathrm{~nm}$ and $405 \mathrm{~nm}$. The $\mathrm{n} \rightarrow \pi^{*}$ transitions can be associated with the presence of heteroatoms (O or $S$ ) within the dye structures. A bathochromic shift can also be observed with an increasing number of electron-donating thiophene or furan moieties within the chemical dye structure. However, for the thienyl derivatives the observed shift is lower than the one for furyl derivatives. For the higher energy band the shift is approximately $35 \mathrm{~nm}$ for thienyl and $50 \mathrm{~nm}$ for furyl derivatives, while for the lower energy band the shift is respectively larger with $55 \mathrm{~nm}$ and $75 \mathrm{~nm}$, respectively. Both, hyperchromic effect and hypochromic effect are also observed for molecules with different numbers of thiophene moieties. Both effects can be associated with the structural symmetry. In non-symmetrical

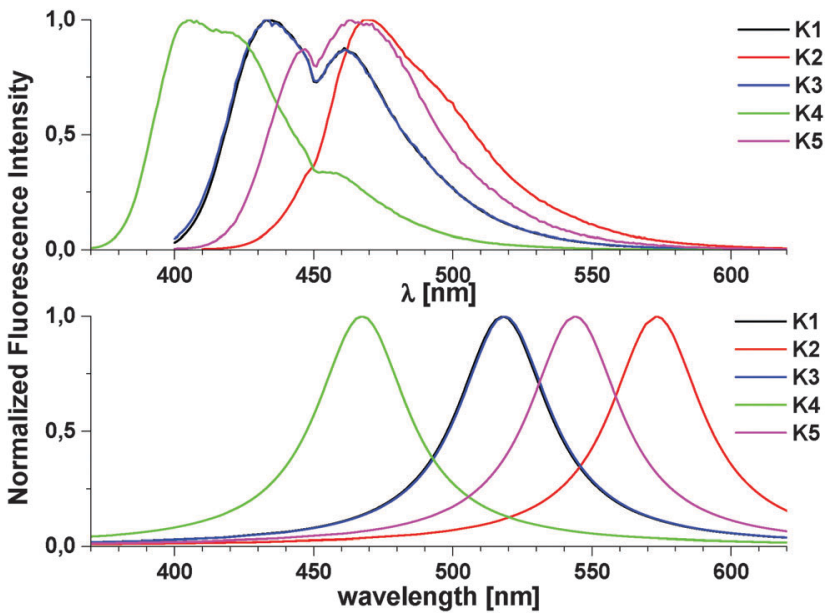

Fig. 7 Experimental (top panel) and TDDFT fluorescence spectra of the pyrene derivatives $\mathbf{K} \mathbf{1 - K 5}$.

systems, the absorption increases with the number of thiophene moieties, while for symmetrical molecules it decreases. Depending on the derivative and the investigated absorption band, molar extinction coefficients $(\varepsilon)$ determined on the basis of the Beer-Lambert law were found in the range of $24000-$ $40000 \mathrm{M}^{-1} \mathrm{~cm}^{-1}$ for thienyl derivatives and in the range of 29000-42000 $\mathrm{M}^{-1} \mathrm{~cm}^{-1}$ for furyl derivatives. Noticeably, the $\varepsilon$ values are basically in the same order of magnitude as the corresponding values for pyrene itself. The summary of parameters determined for thienyl and furyl derivatives based on absorption measurements are presented in Table 1 and Table 2, respectively.

The steady-state fluorescence emission spectra collected for thienyl and furyl derivatives are shown in Fig. 3 and in Fig. 5, respectively. For both classes of compounds, a bathochromic

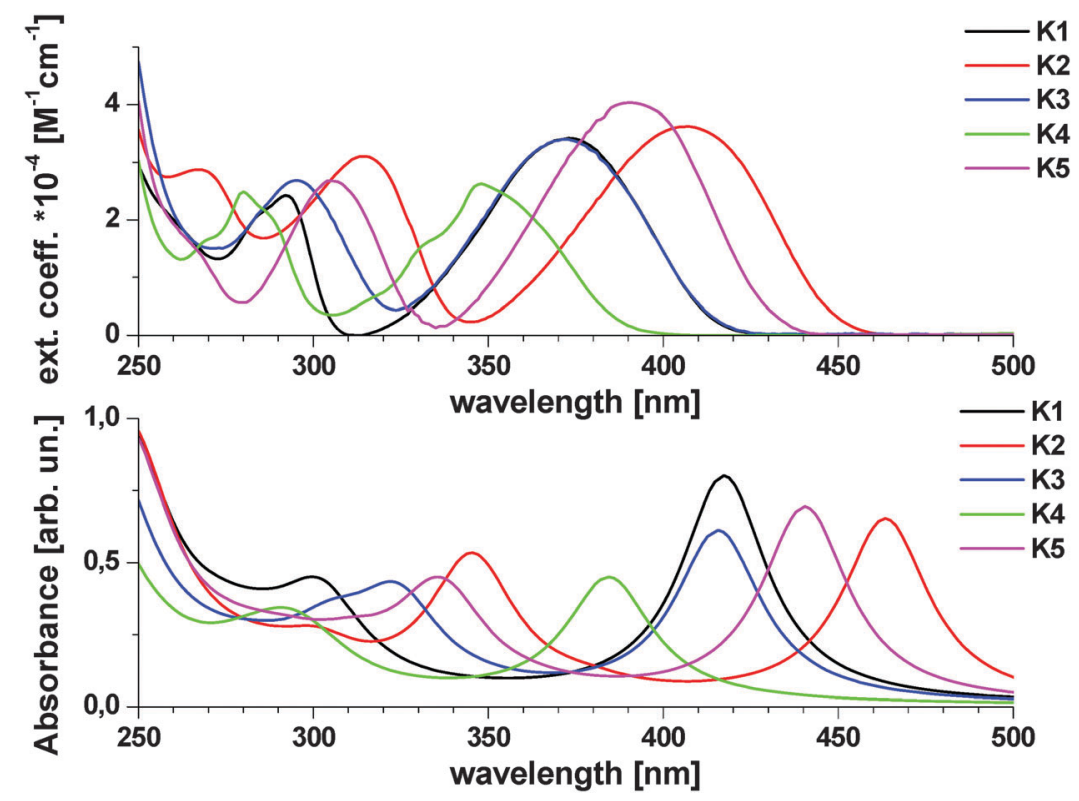

Fig. 6 Experimental (top panel) and TDDFT electronic absorption spectra of the pyrene derivatives K1-K5 
shift is observed with an increasing number of electron-donating (thiophene or furan) groups and the relative ratios between corresponding peaks are different for different derivatives. Noticeably, when two substituents are present within the chemical structure either in cis or trans form, the fluorescence emission spectra are identical, which shows that the position of substituent has no effect on the emission frequencies. This effect has been observed both for thienyl and furyl derivatives.
Importantly, pyrene emission is still dominating in the emission observed for derivatives with only one side group, but for the derivative with four substituents the spectrum is almost completely merged into one bold spectrum, even though the separate peaks can still be recognized. The spectra collected for derivatives with 2 and 3 substitutes are more structured. The merging effect can be associated with decreasing energies due to radiationless deactivation. In all cases, the third band on the

Table 3 Molecular parameters derived from (TD)DFT calculations

\begin{tabular}{|c|c|c|c|c|c|}
\hline & $\begin{array}{l}\text { HOMO } \\
{[\mathrm{eV}]}\end{array}$ & $\begin{array}{l}\text { LUMO } \\
\left(=E_{\mathrm{g}}-\mathrm{HOMO}\right)[\mathrm{eV}]\end{array}$ & $\begin{array}{l}E_{\mathrm{g}} \text { (absorption) } \\
{\left[\mathrm{eV} \mathrm{nm}^{-1}\right]}\end{array}$ & $\begin{array}{l}E_{\mathrm{g}}(\text { emission }) \\
{\left[\mathrm{eV} \mathrm{nm}^{-1}\right]}\end{array}$ & $\begin{array}{l}\text { Average dihedral angle between the } \\
\text { central moiety and the substituents } \\
\text { in ground/excited state [deg] }\end{array}$ \\
\hline K1 & -5.23 & -2.25 & $2.97 / 417$ & $2.39 / 518$ & $133 / 153$ \\
\hline $\mathbf{K} 2$ & -5.15 & -2.47 & $2.68 / 463$ & $2.16 / 573$ & $130 / 144$ \\
\hline K3 & -5.23 & -2.25 & $2.98 / 416$ & $2.39 / 518$ & $131 / 152$ \\
\hline K4 & -5.30 & -2.08 & $3.22 / 384$ & $2.65 / 467$ & $134 / 159$ \\
\hline K5 & -5.18 & -2.37 & $2.81 / 440$ & $2.28 / 544$ & $131 / 148$ \\
\hline
\end{tabular}

Table 4 Graphical representation of HOMO and LUMO orbitals in the studied molecules in the ground and excited states

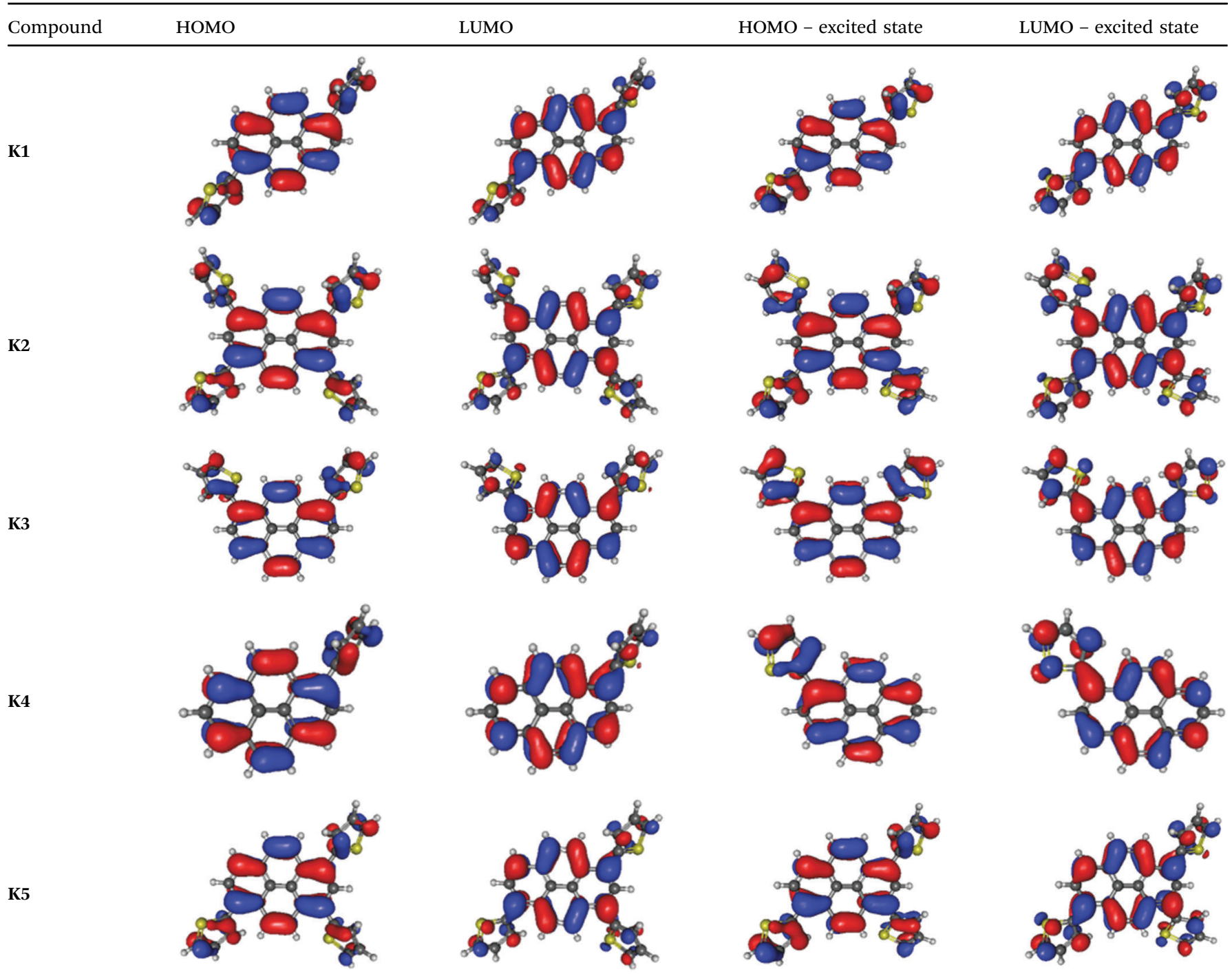



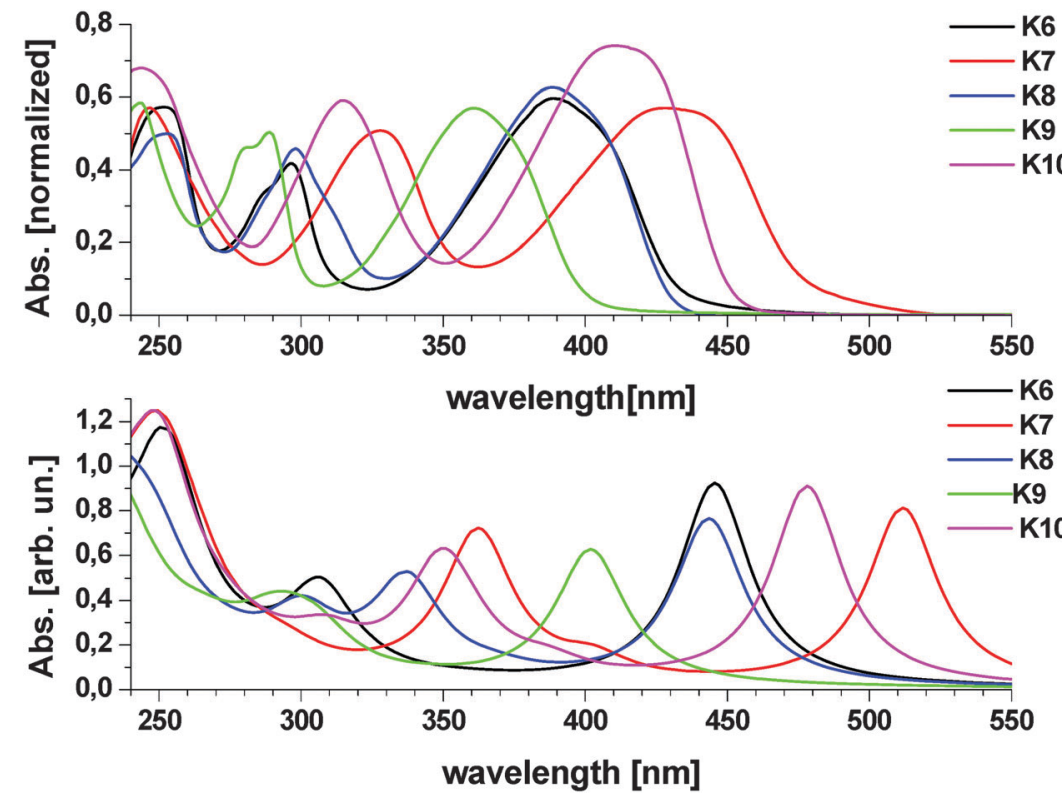

Fig. 8 TDDFT (bottom panel) and experimental (top) absorption spectra of the compounds K6-K10.

spectra stays virtually unaffected and only a red shift is observed for it. Independent from the spectral features similar for both classes of compounds, significant differences in photophysical properties can be noticed when quantum yields $(\Phi)$ and decay times $(\tau)$ are considered. The thienyl derivatives exhibit significantly lower $\Phi(70 \% v s .20 \%)$ and much shorter fluorescence lifetimes (from 0.4 to $0.95 \mathrm{~ns}$ compared to $\sim 2 \mathrm{~ns}$ ) when compared to their furan-substituted counterparts. Noticeably, the fluorescence quantum yield is virtually independent of the number of substituents and their orientation (cis or trans). For the thienyl derivatives the non-radiative processes rate constant $k_{\mathrm{nr}}$ is on average 5 times larger than the radiative process rate constant $k_{\mathrm{f}}$, while for the furyl derivatives $k_{\mathrm{f}}$ was on average two times greater than $k_{\mathrm{nr}}$. This result is a clear

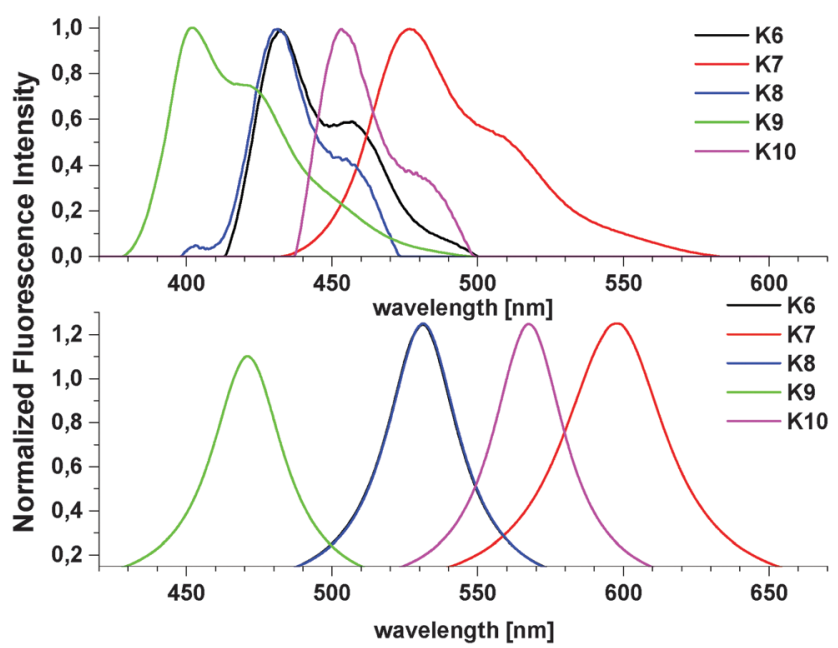

Fig. 9 TDDFT (bottom panel) and experimental (top) fluorescence spectra of the compounds $\mathbf{K} \mathbf{6 - K 1 0}$. $\mathbf{6}$ and $\mathbf{K} \mathbf{8}$ in bottom panel closely overlap. evidence for the domination of the non-radiation processes in the deactivation path of thienyl derivatives. In comparison to furyl derivatives, the thienyl derivatives have larger Stokes shifts on average of about $1000 \mathrm{~cm}^{-1}$. This is another evidence for the domination of non-radiative processes in the thienyl based systems. All the photophysical properties determined for thienyl and furyl pyrene derivatives based on fluorescence measurements are also summarized in Table 1 and Table 2, respectively.

\subsection{Quantum-chemical methods}

3.3.1. Thienyl derivatives of pyrene. The results of the DFT calculations are presented in Fig. 6 and 7 as well as in Tables 3 and 4. All of the studied molecules are optically active, they absorb light in the UV-violet spectral range and emit in the violet-blue part of the spectrum. Noticeably, the theoretical TDDFT predictions are in good agreement with experimental absorption and fluorescence spectra apart from the underestimation of the energy gap by $0.35 \mathrm{eV}$ (equivalent to approximately $70 \mathrm{~nm}$ ). However, this deviation is often encountered in DFT calculations. Nonetheless, the trend along the series K1-K5 is well reproduced in the theoretically derived spectra, including the very close overlapping of $\mathbf{K} \mathbf{1}$ and $\mathbf{K} \mathbf{3}$ in both absorption and emission spectra. The order of the rising energy gap is $\mathbf{K} \mathbf{2}<\mathbf{K} \mathbf{5}<\mathbf{K} \mathbf{1}=\mathbf{K} \mathbf{3}<\mathbf{K} \mathbf{4}$. This is clearly connected to the number of thiophene substituents adding their electrons to the molecular conjugate system. Interestingly, the overlap of K1 and $\mathbf{K} 3$ spectra indicate that in the case of an isomer mixture the relative position of the substituents does not influence the energy levels of HOMO and LUMO orbitals as the substituents contribute to the molecular orbitals in a similar manner (see also Tables 3 and 4).

HOMO and LUMO orbitals are distributed throughout the whole molecule for all studied compounds (Table 4), which is due to the partially planar structures of both ground and 
excited states (Table 3). The large overlap between HOMO and LUMO orbitals results in quite efficient absorptions and emissions.
3.3.2. Furyl derivatives of pyrene. The optical properties of the studied compounds K6-K10 obtained from TDDFT calculations confirm the influence of each additional furan substituent

Table 5 Molecular parameters derived from (TD)DFT calculations

\begin{tabular}{|c|c|c|c|c|c|}
\hline & HOMO $[\mathrm{eV}]$ & $\begin{array}{l}\text { LUMO } \\
\left(=E_{\mathrm{g}}-\mathrm{HOMO}\right)[\mathrm{eV}]\end{array}$ & $\begin{array}{l}E_{\mathrm{g}}(\text { absorption }) \\
{\left[\mathrm{eV} \mathrm{nm}^{-1}\right]}\end{array}$ & $\begin{array}{l}E_{\mathrm{g}} \text { (emission) } \\
{\left[\mathrm{eV} \mathrm{nm}^{-1}\right]}\end{array}$ & $\begin{array}{l}\text { Average dihedral angle between the } \\
\text { central moiety and the substituents } \\
\text { in ground/excited state [deg] }\end{array}$ \\
\hline K6 & 5.10 & 2.32 & $2.78 / 446$ & $2.33 / 531$ & $150 / 164$ \\
\hline K8 & 5.09 & 2.29 & $2.80 / 443$ & $2.33 / 531$ & $149 / 168$ \\
\hline K9 & 5.23 & 2.14 & $3.09 / 402$ & $2.63 / 471$ & $150 / 168$ \\
\hline K10 & 5.02 & 2.43 & $2.59 / 478$ & $2.18 / 568$ & $151 / 162$ \\
\hline
\end{tabular}

Table 6 Graphic representation of HOMO and LUMO orbitals in the studied molecules in the ground and excited states

Compound HOMO LUMO HOMO - excited state LUMO - excited state
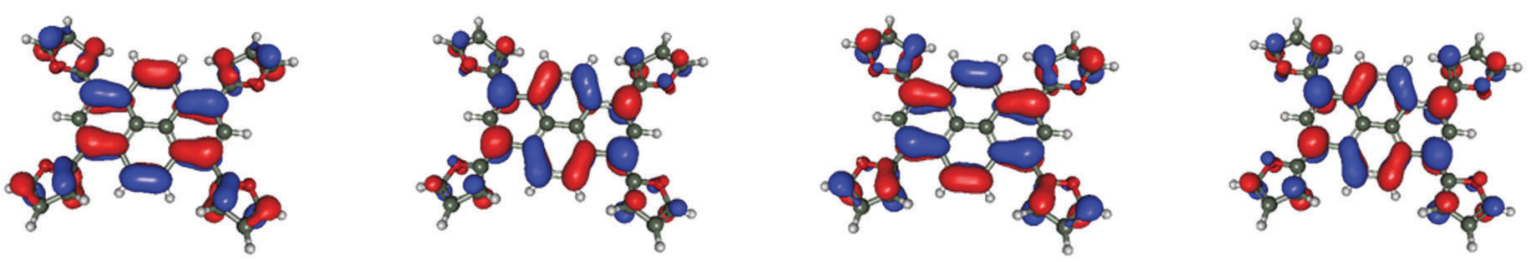

K8
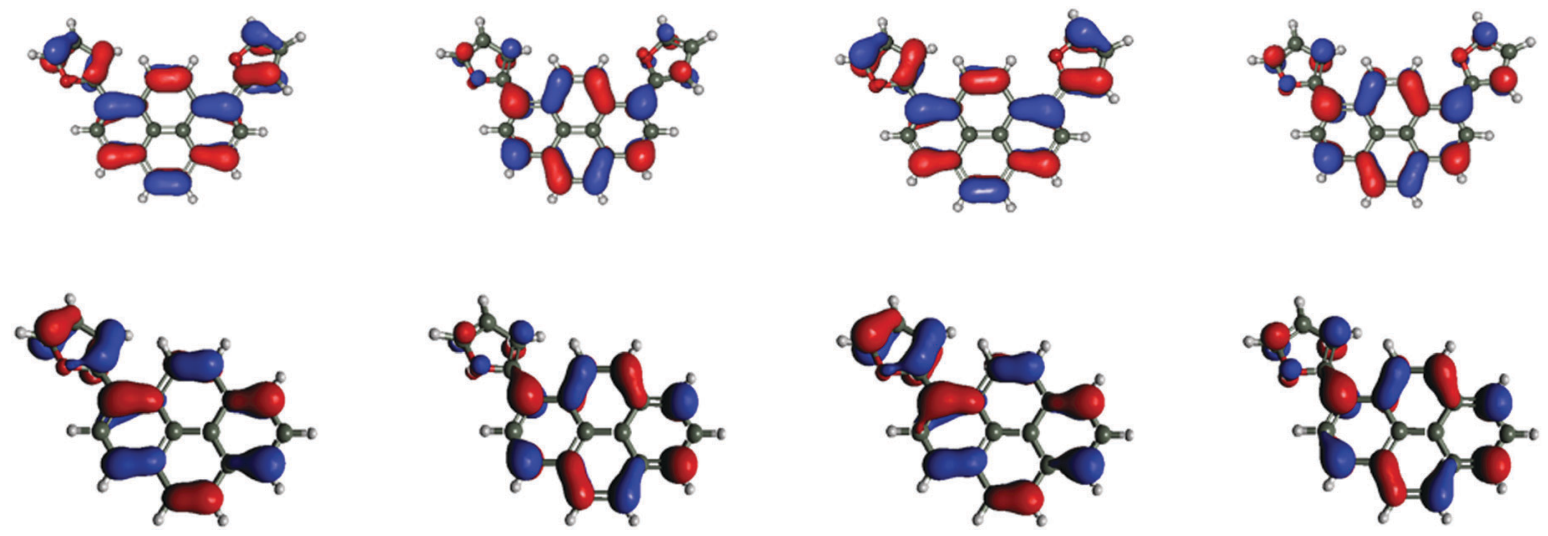

K10
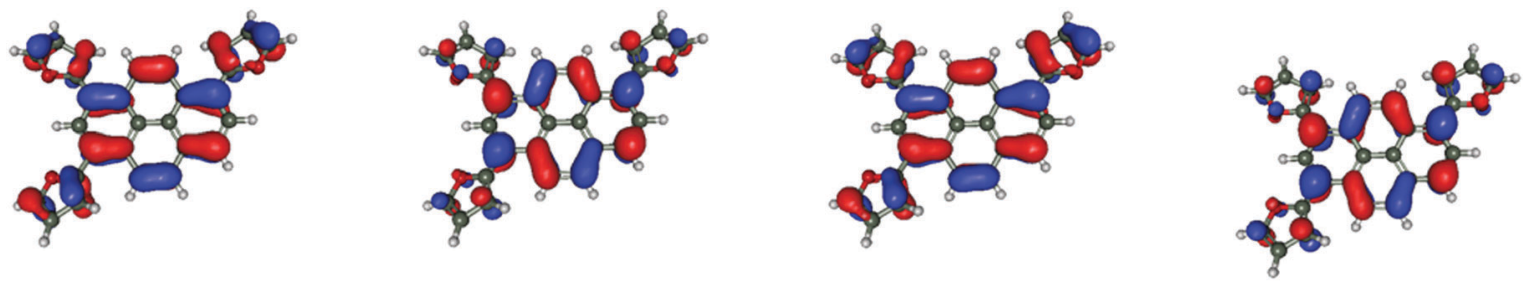
Table 7 Melting point of thienyl and furyl derivatives of pyrene

\begin{tabular}{|c|c|c|c|c|c|c|c|c|c|c|}
\hline Compound & K1 & K2 & K3 & $\mathbf{K 4}$ & K5 & K6 & K7 & K8 & K9 & K10 \\
\hline
\end{tabular}

on the absorption and emission properties (Fig. 8 and 9, Table 5). The TDDFT-predicted UV-VIS absorption spectra presented in Fig. 8 are in very good agreement with experimental data apart from the underestimation of the energy gap by approximately $0.4 \mathrm{eV}$ commonly encountered in such calculations. Nevertheless, the relative spectral positions of the lowest energy absorption peak, attributed by the TDDFT calculations to the HOMO-LUMO transition, are reproduced well in the calculation. The order of the rise in the energy gap is $\mathbf{K 7}<\mathbf{K 1 0}<\mathbf{K 6}=\mathbf{K 8}<\mathbf{K 9}$ and this is also found in the emission spectra, both theoretically derived and experimentally observed (Fig. 9). It is quite clear that the HOMOLUMO energy gap and the related optical properties depend on the number of furene substituents attached to the pyrene molecule. Interestingly, the spectra measured for the $\mathbf{K 6}$ and $\mathbf{K 8}$ compounds with two furyl units in trans- and cis- positions respectively, are nearly overlapping. Apparently, the contribution of the furyl substituents to the crucial HOMO and LUMO orbitals is independent of their position in the compounds, as can be seen in Table 6.

\subsection{OLED preparation}

Fig. 1 shows the layer structure of the OLED device with details on the used organic compounds and the function of each layer. Indium tin oxide (ITO)-coated glass (size $5 \times 5 \mathrm{~cm}$ ) with a sheet resistance of about $8-12 \Omega \mathrm{sq}^{-1}$ was used as the backing material. ITO deposited on the glass was cleaned by sonication in a detergent solution and then rinsed using de-ionized water.

An aqueous solution of PEDOT/PSS (poly(3,4-ethylenedioxythiophene)/poly(styrenesulfonate)) (HTL) forming a hole conductive layer, was deposited onto ITO. Then water was removed under low pressure in a nitrogen atmosphere. The light-emitting layer (EML) (thienyl and furyl derivatives of pyrene) was deposited

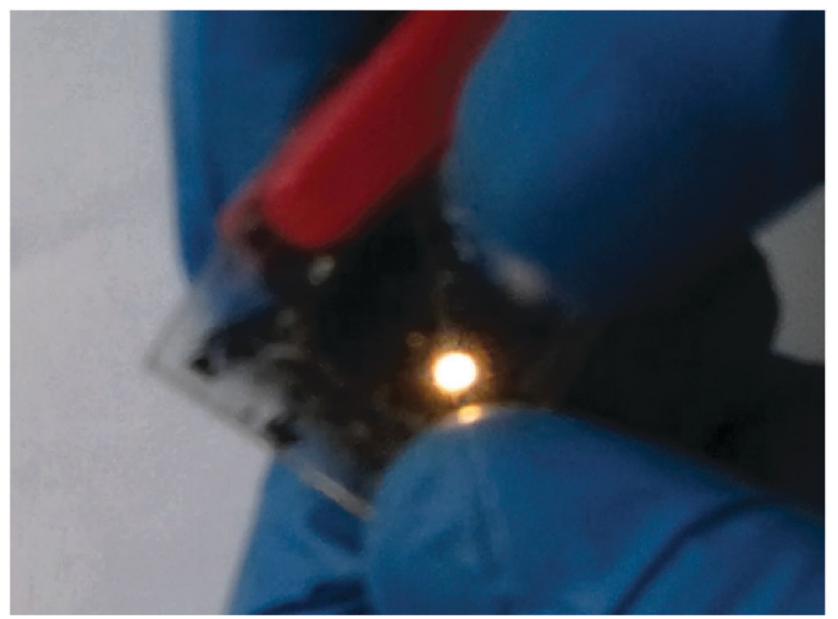

Fig. 10 Effect of the organic light-emitting diodes made from 1,3,6,8tetra(2-furyl)-pyrene. on the cathode, which was an aluminum plate of size $0.5 \times 0.5 \mathrm{~cm}$. Plates were superimposed onto each other. Then, the device was connected to a DC power source and a $24 \mathrm{~V}$ voltage was passed through it to give a current equal to $0.2 \mathrm{~A}$. A bright light with a color characteristic for the corresponding pyrene derivatives was observed under such conditions. Fig. 10 displays the working diode prepared using 1,3,6,8-tetra(2-furyl)-pyrene as an active emitting layer.

\section{Conclusions}

In this work we have presented photophysical properties and theoretical calculations for two new classes of low molecular weight materials based on a pyrene core substituted either with thiophene or furan units. All studied molecules can absorb light in the UV or violet visible range and emit in the blue-violet spectral region. We observed that the replacement of the thiophene by furan increases the fluorescence quantum yield, most likely due to the more planar structure of the former allowing for a efficient contribution of the $\pi$ electrons. Furthermore, we described DFT calculations and TDDFT simulations for the presented materials. These quantum-chemical calculations fully support obtained experimental data. HOMO and LUMO orbitals are delocalized uniformly on the pyrene core and its aryl substituents. Theoretical calculations provided values for the HOMO-LUMO gaps for the neutral states of the compounds. Compounds described in this paper fulfill the technological requirements for materials to be successfully applied in the construction of organic-electronic devices as demonstrated by the OLED device presented in this paper. In order to verify the practical usefulness of the synthetized materials we built a prototype diode (OLED) using thienyl and furyl derivatives of pyrene and also bithienyl derivatives of triazine. Obtained OLEDs emitted blue light at a voltage of $12 \mathrm{~V}$ and a yellow light at a voltage of $24 \mathrm{~V}$. Following the physico-chemical measurements and a successful practical application in OLEDs, the synthesized heterocyclic units can be used as innovative, efficient, cost-effective and environmentally friendly (mercury free) materials for light sources. These units can be flexibly designed and emit a broad spectrum of visible light, when appropriately tuned. The manufacturing of this type of light sources is one of the global research priorities, because it is based on a combination of new organic materials and economic production methods, thus enabling a variety of innovative products to be designed. Considerable progress in nanotechnology that has been made in recent years has resulted in the launch of the first electronic products made of organic materials.

\section{Acknowledgements}

This work was supported within the research grant no 2011/01/N/ ST4/02251 from National Science Centre, Poland. Calculations have 
been carried out in Wroclaw Centre for Networking and Supercomputing (http://www.wcss.wroc.pl, grant No.135). The presented study was partially funded by the German Federal Ministry of Environment (promotional reference No. 0325417, Reaktherm).

\section{References}

1 C. W. Tang and S. A. VanSlyke, Appl. Phys. Lett., 1987, 51, 913-915.

2 Y. Sun, N. C. Giebink, H. Kanno, B. Ma, M. E. Thompson and S. R. Forrest, Nature, 2006, 440, 908-912.

3 J. M. Hancock, A. P. Gifford, Y. Zhu, Y. Lou and S. A. Jenekhe, Chem. Mater., 2006, 18, 4924-4932.

4 P. L. Burn, S. C. Lo and D. W. Samuel, Adv. Mater., 2007, 19, 1675-1688.

5 Y. Y. Lyu, O. Kwak, J. Kwon, S. H. Lee, D. Kim, C. Lee and K. Char, Adv. Mater., 2008, 20, 2720-2729.

6 C. J. Tonzola, A. P. Kulkarni, A. P. Gifford, W. Kaminsky and S. A. Jenekhe, Adv. Funct. Mater., 2007, 17, 863-874.

7 S. Tao, Y. Zhou, C. S. Lee, X. Zhang and S. T. Lee, Chem. Mater., 2010, 22, 2138-2141.

8 L. Duan, L. Hou, T. W. Lee, J. Qiao, D. Zhang, G. Dong, L. Wang and Y. J. Qiu, J. Mater. Chem., 2010, 20, 6392-6407.

9 X. Zhan, Z. A. Tan, B. Domercq, Z. An, X. Zhang, S. Barlow, Y. Li, D. Zhu, B. Kippelen and S. R. Marder, J. Am. Chem. Soc., 2007, 129, 7246-7247.

10 A. B. F. Martinson, T. W. Hamann, M. J. Pellin and J. T. Hupp, Chem. - Eur. J., 2008, 14, 4458-4467.

11 M. Velusamy, J.-H. Huang, Y.-C. Hsu, H.-H. Chou, K.-C. Ho, P.-L. Wu, W.-H. Chang, J. T. Lin and C.-W. Chu, Org. Lett., 2009, 11, 4898-4901.

12 Z. Ning and H. Tian, Chem. Commun., 2009, 5483-5495.

13 A. Hagfeldt, G. Boschloo, L. Sun, L. Kloo and H. Pettersson, Chem. Rev., 2010, 110, 6595-6663.

14 J. N. Clifford, E. Martínez-Ferrero, A. Viterisi and E. Palomares, Chem. Soc. Rev., 2011, 40, 1635-1646.

15 X. W. Zhan, A. Facchetti, S. Barlow, T. J. Marks, M. A. Ratner, M. R. Wasielewski and S. R. Marder, Adv. Mater., 2011, 23, 268-284.

16 V. C. Sundar, J. Zaumseil, V. Podzorov, E. Menard, R. L. Willett, T. Someya, M. E. Gershenson and J. A. Rogers, Science, 2004, 303, 1644-1647.

17 Y. M. Sun, Y. Q. Liu and D. B. Zhu, J. Mater. Chem., 2005, 15, 53-65.

18 M. Mas-Torrent and C. Rovira, J. Mater. Chem., 2006, 16, 433-436.

19 B. J. Jung, N. J. Tremblay, M.-L. Yeh and H. E. Katz, Chem. Mater., 2011, 23, 568-582.

20 K. Niimi, S. Shinamura, I. Osaka, E. Miyazaki and K. Takimiya, J. Am. Chem. Soc., 2011, 133, 8732-8739.

21 F. Terenziani, A. Painelli, C. Katan, M. Charlot and M. Blanchard-Desce, J. Am. Chem. Soc., 2006, 128, 15742-15755.

22 F. Terenziani, G. D'Avino and A. Painelli, ChemPhysChem, 2007, 8, 2433-2444.

23 F. Rizzo, M. Cavazzini, S. Righetto, F. De Angelis, S. Fantacci and S. Quici, Eur. J. Org. Chem., 2010, 4004-4016.
24 M. Nakano, R. Kishi, K. Yoneda, Y. Inoue, T. Inui, Y. Shigeta, T. Kubo and B. Champagne, J. Phys. Chem. A, 2011, 115, 8767-8777.

25 Y. Sun, N. C. Giebink, H. Kanno, B. Ma, M. E. Thompson and S R. Forrest, Nature, 2006, 440, 908-912.

26 J. M. Hancock, A. P. Gifford, Y. Zhu, Y. Lou and S. A. Jenekhe, Chem. Mater., 2006, 18, 4924-4932.

27 Y. Y. Lyu, J. Kwak, O. Kwon, S. H. Lee, D. Kim, C. Lee and K. Char, Adv. Mater., 2008, 20, 2720-2729.

28 C. J. Tonzola, A. P. Kulkarni, A. P. Gifford, W. Kaminsky and S. A. Jenekhe, Adv. Funct. Mater., 2007, 17, 863-874.

29 L. Duan, L. Hou, T. W. Lee, J. Qiao, D. Zhang, G. Dong, L. Wang and Y. J. Qiu, J. Mater. Chem., 2010, 20, 6392-6407.

30 C. W. Tang and S. A. VanSlyke, Appl. Phys. Lett., 1987, 51, 913-915.

31 P. L. Burn, S. C. Lo and D. W. Samuel, Adv. Mater., 2007, 19, 1675-1688.

32 S. Tao, Y. Zhou, C. S. Lee, X. Zhang and S. T. Lee, Chem. Mater., 2010, 22, 2138-2141.

33 L. Pu, Chem. Rev., 2004, 104, 1687.

34 R. Martinez-Manez and F. Sancenon, Chem. Rev., 2003, 103, 4419.

35 H. Yuasa, N. Miyagawa, T. Izumi, M. Nakatani, M. Izumi and H. Hashimoto, Org. Lett., 2004, 6, 1489.

36 H. Abe, Y. Mawatari, H. Teraoka, K. Fujimoto and M. Inouye, J. Org. Chem., 2004, 69, 495.

37 Y. Hassheider, S. A. Benning, H. S. Kitzerow, M. F. Achard and H. Bock, Angew. Chem., Int. Ed., 2001, 40, 2060.

38 V. De Halleux, J. P. Calbert, P. Brocorens, J. Cornil, J. P. Declercq, J. L. Brédas and Y. Geerts, Adv. Funct. Mater., 2004, 14, 649.

39 G. Jones and V. I. Vullev, Org. Lett., 2002, 4, 4001.

40 J. Daub, R. Engl, J. Kurzawa, S. E. Miller, S. Schneider, A. Stockmann and M. R. Wasielewski, J. Phys. Chem. A, 2001, $105,5655$.

41 M. C. Jobanputra, M. F. Durstock and S. F. Clarson, J. Appl. Polym. Sci., 2003, 87, 523.

42 L. T. Cheng, W. Tam, S. H. Stevenson, G. R. Meredith and G. Rikken, J. Phys. Chem., 1991, 95, 10643.

43 A. K.-Y. Jen, Y. Cai, P. V. Bedworth and S. R. Marder, Adv. Mater., 1997, 9, 132.

44 B. R. Cho, K. N. Son, S. J. Lee and T. J. Kang, Tetrahedron Lett., 1998, 39, 3167.

45 S. S. P. Chom and C. H. Shen, Tetrahedron Lett., 1997, 38, 6407.

46 H. Sirringhaus, Adv. Mater., 2005, 17, 2411.

47 A. Mishra, C. Q. Ma and P. Bäuerle, Chem. Rev., 2009, 109, 1141.

48 W. Ma, C. Yang, X. Gong and K. Lee, Adv. Funct. Mater., 2005, 15, 1617.

49 F. Padinger, R. S. Rittberger and N. S. Sariciftci, Adv. Funct. Mater., 2003, 13, 85.

50 Y. Shirota, J. Mater. Chem., 2000, 10, 1.

51 P. Liu, Y. Shirota and Y. Osada, Polym. Adv. Technol., 2000, 11, 512.

52 P. Liu, H. Nakano and Y. Shirota, Liq. Cryst., 2001, 28, 581. 
53 P. Liu, X. B. Wang, Y. M. Zhang, X. P. Zhou and W. J. Deng, Synth. Met., 2005, 155, 565.

54 P. Liu, M. S. Huang, W. Z. Pan, Y. M. Zhang and W. J. Deng, J. Lumin., 2006, 121, 109.

55 P. Liu, M. M. Liu and W. J. Deng, Synth. Commun., 2006, 36, 685.

56 P. Liu, Y. G. Wang, W. Z. Pan, M. S. Huang and W. J. Deng, Chin. J. Chem., 2006, 24, 1305.

57 M. C. Jobanputra, M. F. Durstock and S. F. Clarson, J. Appl. Polym. Sci., 2003, 87, 523.

58 L. T. Cheng, W. Tam, S. H. Stevenson, G. R. Meredith and G. Rikken, J. Phys. Chem., 1991, 95, 10643.

59 H. Tsuji, C. Mitsui, L. Ilies, Y. Sato and E. Nakamura, J. Am. Chem. Soc., 2007, 129, 11902.

60 Y. Miyata, M. Terayama, T. Minari, T. Nishinaga, T. Nemoto, S. Isoda and K. Komatsu, Chem. - Asian J., 2007, 2, 1492.

61 J. C. Bijleveld, B. P. Karsten, S. G. J. Mathijssen, M. M. Wienk, D. M. de Leeuw and R. A. J. Janssen, J. Mater. Chem., 2011, 21, 1600.

62 Y. Li, P. Sonar, S. P. Singh, W. Zeng and M. S. Soh, J. Mater. Chem., 2011, 21, 10829.

63 O. Gidron, Y. Diskin-Posner and M. Bendikov, J. Am. Chem. Soc., 2010, 132, 2148.

64 O. Gidron, A. Dadvand, Y. Sheynin, M. Bendikov and D. F. Perepichka, Chem. Commun., 2011, 47, 1976.

65 L. Huo, Y. Huang, B. Fan, X. Guo, Y. Jing, M. Zhang, Y. Li and J. Hou, Chem. Commun., 2012, 48, 3318.

66 C. Mitsui, J. Soeda, K. Miwa, H. Tsuji, J. Takeya and E. Nakamura, J. Am. Chem. Soc., 2012, 134, 5448.

67 M. Jones Jr, Organic Chemistry, 3rd edn, 2005.

68 A. Juric, A. Sabljic and N. Trinajstic, J. Heterocycl. Chem., 1984, 21, 273.

69 Z. Q. Gao, C. S. Lee, I. Bello, S. T. Lee, R. M. Chen, T. Y. Luh, J. Shi and C. W. Tang, Appl. Phys. Lett., 1999, 74, 865.

70 A. P. Kulkarni, A. P. Gifford, C. J. Tonzola and S. A. Jenekhea, Appl. Phys. Lett., 2005, 86, 061106.

71 J. M. Shi and C. W. Tang, Appl. Phys. Lett., 2002, 80, 3201.

72 D. Gebeyehu, K. Walzer, G. He, M. Pfeiffer, K. Leo, J. Brandt, A. Gerhard, P. Stössel and H. Vestweber, Synth. Met., 2005, 148, 205.

73 C. Hosokawa, H. Higashi, H. Nakamura and T. Kusumoto, Appl. Phys. Lett., 1995, 67, 3853.

74 C. H. Liao, M. T. Lee, C. H. Tsai and C. H. Chen, Appl. Phys. Lett., 2005, 86, 203507.
75 Y. Z. Wu, X. Y. Zheng, W. Q. Zhu, R. G. Sun, X. Y. Jiang, Z. L. Zhang and S. H. Xu, Appl. Phys. Lett., 2003, 83, 5077.

76 L. Duan, L. Hou, T. Lee, J. Qiao, D. Zhang, G. Dong and L. Wang L, Mater. Chem., 2010, 20, 6392.

77 G.-F. Wang, X.-M. Tao, J. H. Xin and B. Fei, Nanoscale Res. Lett., 2009, 4, 613.

78 C. h. Zhong, C. h. Duan, F. Huang, H. Wu and Y. Cao, Chem. Mater., 2011, 23, 326.

79 M. S. AlSalhi, J. Alam, L. A. Dass and M. Raja, Int. J. Mol. Sci., 2011, 12, 2036.

80 M. J. Frisch, G. W. Trucks, H. B. Schlegel, G. E. Scuseria, M. A. Robb, J. R. Cheeseman, G. Scalmani, V. Barone, B. Mennucci, G. A. Petersson, H. Nakatsuji, M. Caricato, X. Li, H. P. Hratchian, A. F. Izmaylov, J. Bloino, G. Zheng, J. L. Sonnenberg, M. Hada, M. Ehara, K. Toyota, R. Fukuda, J. Hasegawa, M. Ishida, T. Nakajima, Y. Honda, O. Kitao, H. Nakai, T. Vreven, J. A. Montgomery Jr, J. E. Peralta, F. Ogliaro, M. Bearpark, J. J. Heyd, E. Brothers, K. N. Kudin, V. N. Staroverov, T. Keith, R. Kobayashi, J. Normand, K. Raghavachari, A. Rendell, J. C. Burant, S. S. Iyengar, J. Tomasi, M. Cossi, N. Rega, J. M. Millam, M. Klene, J. E. Knox, J. B. Cross, V. Bakken, C. Adamo, J. Jaramillo, R. Gomperts, R. E. Stratmann, O. Yazyev, A. J. Austin, R. Cammi, C. Pomelli, J. W. Ochterski, R. L. Martin, K. Morokuma, V. G. Zakrzewski, G. A. Voth, P. Salvador, J. J. Dannenberg, S. Dapprich, A. D. Daniels, O. Farkas, J. B. Foresman, J. V. Ortiz, J. Cioslowski and D. J. Fox, Gaussian 09, Revision B.01, Gaussian, Inc., Wallingford CT, 2010.

81 A.R. Allouche, Gabedit is a free graphical user interface for computational chemistry packages. Available at: http://gabe dit.sourceforge.net/.

82 S. Miertus, E. Scrocco and J. Tomasi, J. Chem. Phys., 1981, $55,117$.

83 P. Machata, P. Rapta, V. Lukes, K. R. Idzik, T. Licha, R. Beckert and L. Dunsch, Electrochim. Acta, 2014, 122, 57-65.

84 K. R. Idzik, P. Ledwon, T. Licha, W. Kuznik, M. Lapkowski and J. Frydel, Dyes Pigm., 2014, 103, 55-61.

85 K. R. Idzik, T. Licha, V. Lukes, P. Rapta, J. Frydel, M. Schaffer, E. Taeuscher, R. Beckert and L. Dunsch, J. Fluoresc., 2014, 24(1), 153-160.

86 P. Ledwon, M. Lapkowski, T. Licha, J. Frydel and K. R. Idzik, Synth. Met., 2014, 191, 74-82. 